\title{
Effect of Water Content on Brightness Temperature and Emissivity of Soil for Passive Remote Sensing Applications
}

\author{
Falih A. Aziz \\ College of Pharmacy \\ University of Mosul
}

(Received 27/11/2012, Accepted 16/7/2013)

\begin{abstract}
The relative complex dielectric constant $\left(\boldsymbol{\varepsilon}_{\mathbf{r}}=\boldsymbol{\varepsilon}_{\mathbf{1}} \mathbf{j} \mathbf{j} \boldsymbol{\varepsilon}_{\mathbf{2}}\right)$ of a number of sandy soil samples from the Markib seashore, in Libya has been measured as a function of moisture content at microwave frequency in the $\mathrm{X}$-band $(\mathrm{f}=10.7 \mathrm{GHz}, \lambda=2.8 \mathrm{~cm})$ and L-band $(\mathrm{f}=1.4 \mathrm{GHz}, \lambda=21 \mathrm{~cm})$. A knowledge of the complex dielectric constant of soils is essential in the interpretation of microwave airborne radiometer data of the Earth's surface. The reflectivity and emissivity of smooth surface have been calculated in both polarizations at various nadir angles using the measured laboratory data. It has been found that the emissivity decreases at larger angles of incidence for horizontal polarization, whereas it increases at vertical polarization with increasing incidence angle to a maximum at the Brewster angle. It has also been observed that the incidence angle, at which the Brewster angle occurs, shifts toward grazing for higher percent moisture content. The brightness temperature of dry and wet soil has been computed in both horizontal and vertical polarization mode as a function of physical temperature and dielectric constant of each soil with varying moisture content. The brightness temperature of dry and wet soil depend on dielectric constant, physical properties, polarization and the angle of incidence of microwaves. These facts are especially important and can be used as diagnostic tool for water prospecting in deserts.
\end{abstract}

Keywords: Dielectric Constant, Passive Microwave Radiometer, Soil moisture Content, Brightness Temperature, Emissivity.

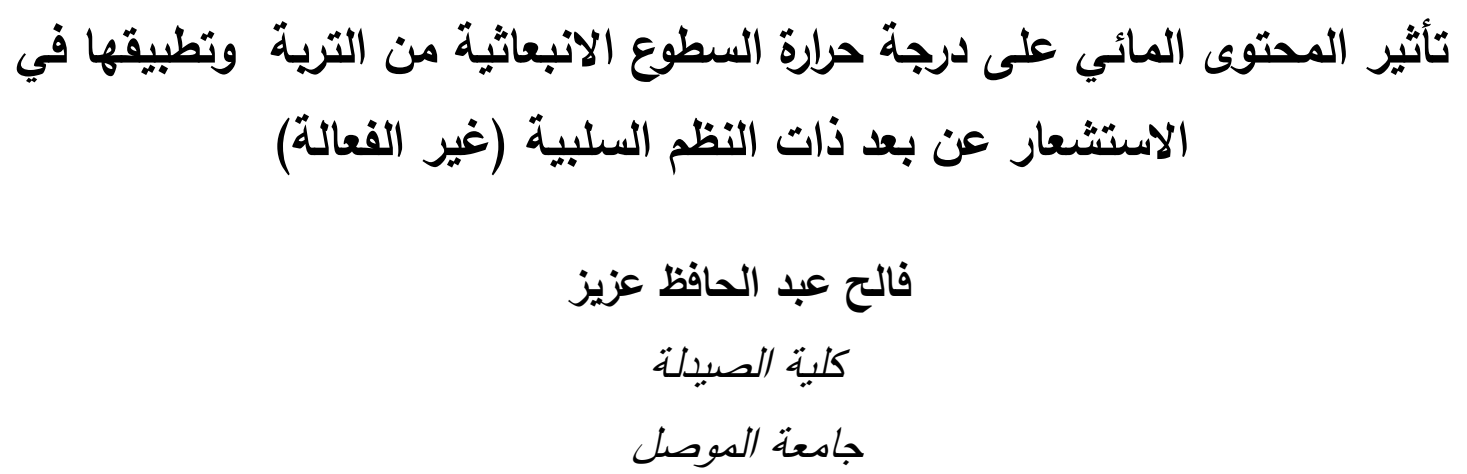




\section{الملخص}

تم استخدام سلسلة من التجارب في هذه الدراسة التي تم التحكم بها مختبريا" باستخدام منظومة معينة

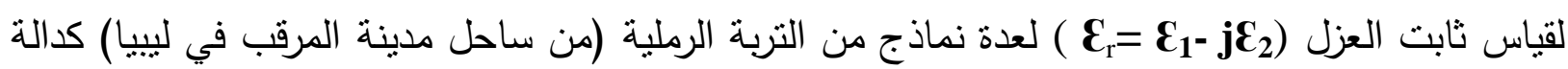

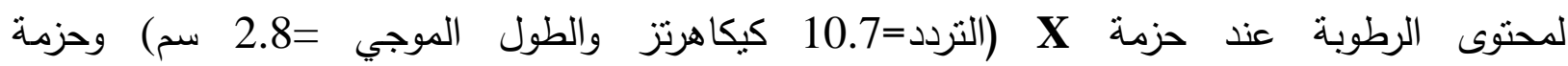
التردد=1.4 كيكاهرتز والطول الموجي =21 سم) للموجات المايكروية. إذ تم إعداد نموذج (model) L الذي يصف ويقيم منظومة التربة - الماء- الهواء، ذلك ان تركيز الماء في التربة يؤثر على خاصية ثابت العزل، معرفة ثابت العزل للتربة ضروري وأساسي إذ يساعد في تفسير بيانات مقاييس الإنشعاع المايكروية

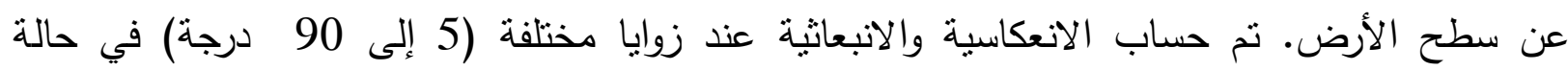
الاستقطاب العمودي والاستقطاب الأفقي وباستعمال البيانات المقاسة عن ثابت العزل. وقد وجد أن الانبعاثية

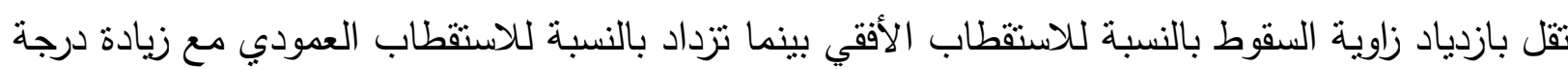
السقوط إلى أن تصل زاوية بروستر ( قليلا عندما تزداد الرطوبة. وتم حساب درجة حرارة السطوع لمحتوى الرطوبة للتربة لكلا الاستقطابين كدالة

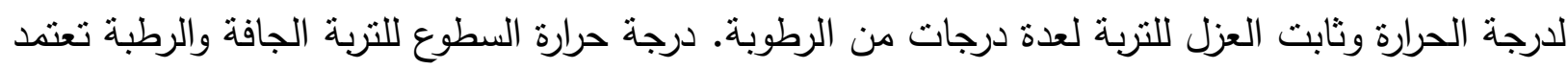

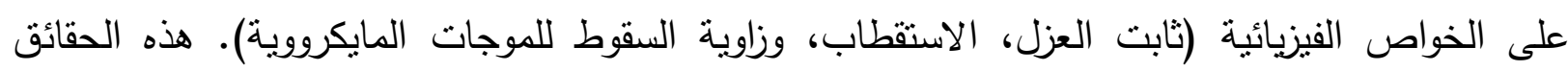
الأساسية مهمة جدا ويمكن اعتبارها كأجهزة تتخيصية للتنقيب عن أماكن وجود الماء في الصحراء. الكلمات الدالة: ثابت العزل للتربة، حرارة السطوع، الانبعاثية، الموجات المايكرويه، التحسس النهائه النائي.

\section{INTRODUCTION}

A principal goal of soil moisture remote sensing research is the evaluation and development of remote sensing technology for measuring and monitoring soil moisture. A secondary goal is to improve existing water management procedures through the use of this technology. Methods used to measure soil moisture content can be divided into two broad classes. The first which relies on direct contact with the soil, includes the gravimetric, resistance, neutron probe and suction methods, among others. The remote sensing methods can be subdivided according to the region of the electromagnetic spectrum used for sensing the surface (Ulaby, 1974).

1- Visible remote sensing techniques.

2- Thermal Infrared techniques.

3- Microwave remote sensing techniques. 
The dielectric constant of soil is found to be strongly dependent on moisture content (Pancholi and Khameshra, 1994; Srivastava and Mishra, 2004; Gadani and Vyas; 2008). The dielectric constant of soil is a measure of the response of the soil to an electromagnetic wave. This response is composed of two parts (real and imaginary), which determine the wave velocity and energy loss, respectively. In a non-homogeneous medium, such as soil, the bulk dielectric constant is a combination of the individual dielectric constants of its components (i.e. Air, water, dry soil, etc...), but is not a weighted average. The large contrast between the dielectric constant of air $\left(\mathcal{E}_{\mathrm{a}} \approx 1\right)$, dry soil ( $\left.\mathcal{E}_{\mathrm{s}} \approx 2-4\right)$ (Uluby et al., $1986)$ and water $\left(\varepsilon_{\mathrm{w}} \approx 80\right)$ in microwave region, results in a range of the bulk dielectric constant from 2 to 40 for a soil-water interface. Calla, (2000) has predicted that the microwave emission depends upon the dielectric constant of the soil. Further, (Sucher and Fox; 1963); (Vyas and Gadam, 2001) have measured the dielectric constant of dry and wet soil in frequency range $(2 \mathrm{GHz})$ to $(20 \mathrm{GHz})$. Yadav and Gandhi, (1992) suggested a simple microwave technique to measure the dielectric property of solids and their powder. The present study has undertaken to have a comprehensive idea of dielectric properties of sand soils of the Markib seashore, Libya.

In this paper, the experimentally determined values of the real and imaginary parts of the complex dielectric constant have been shown for sand samples with varied moisture content, and found that the dielectric constant of these soil samples increases slowly with increasing moisture content up to transition moisture, after which it increases rapidly with the increase in moisture content in the soil. From the measured value of dielectric constant, the emissivity and brightness temperature of soil at a given frequency can be calculated. The emissivity is an important parameter for microwave remote sensing, which provides information about soils. Thus the knowledge of variation of dielectric constant with moisture content of a soil is useful for the interpretation of data obtained for microwave remote sensing application, e.g. agriculture, hydrology and meteorology.

Interpretation and analysis of microwave measurements require model calculations of the brightness temperature for a range of moisture and temperature profiles. Several radiative transfer models have been developed for such calculations (Njoku and Kong,1977; Wilheit,1978). These models require detailed solutions of Maxwell's equations for electromagnetic waves propagating through stratified layers of the dielectric media. Accuracy of the calculations depends on the knowledge of the dielectric properties of the soil medium. The radiative transfer model developed by (Wilheit,1978) is particularly suited for calculating the brightness temperature of the dry and wet soil. 


\section{THEORETICAL CONSIDERATION}

\section{I-Relation between complex permittivity and propagation constant:}

The propagation of electromagnetic wave through a medium depends upon the electrical conductivity, complex dielectric constant $\left(\boldsymbol{E}^{*}\right)$, magnetic permeability $(\mu)$, and the frequency (f) through the propagation constant $(\gamma)$. The relative complex dielectric constant $\left(\boldsymbol{\varepsilon}_{\mathbf{r}}\right)$ of the medium is defined by using the basic principles of Maxwell's equations (Stratton, 1944; Ramo et al., 1965).

$\varepsilon_{\mathrm{r}}=\varepsilon^{*} / \varepsilon_{\mathrm{o}}=\varepsilon_{1}-\mathrm{j} \varepsilon_{2}$ 1

Where $\boldsymbol{\varepsilon}_{\mathbf{1}}$ is the real part of the complex dielectric constant, $\boldsymbol{\varepsilon}_{\mathbf{2}}$ is the imaginary part of the complex dielectric constant and $\boldsymbol{\varepsilon}_{\mathbf{0}}$ is the free space permittivity. The real and imaginary parts of the dielectric constant are expressed (Ramo et al., 1965) as:

$\varepsilon_{1}=\left(\beta^{2}-\alpha^{2}\right) / w^{2} \mu \varepsilon_{o}$

$\varepsilon_{2}=2 \alpha \beta / \mathrm{w}^{2} \mu \varepsilon_{\mathrm{o}}$ .3

Where $\boldsymbol{\alpha}$ is the attenuation constant, $\boldsymbol{\beta}$ is the phase constant and $\mathbf{w}$ is the angular frequency of the wave. At microwave frequencies for non-magnetic materials (Sucher and Fox, 1963) such that $\boldsymbol{\mu}=\boldsymbol{\mu}_{\mathbf{0}}$ (is the permeability of the free space), equations ( 2 and 3 ) are written as:

$\varepsilon_{1}=\left(\beta^{2}-\alpha^{2}\right) / \beta_{0}^{2}$

$\varepsilon_{2}=2 \alpha \beta / \beta_{0}{ }^{2}$

Where $\boldsymbol{\beta}_{0}$ is the phase constant of free space and is given as $\boldsymbol{\beta}_{0}=\mathbf{w} \sqrt{\boldsymbol{\mu}_{0} \varepsilon_{0}}$ Thus the relative complex dielectric constant is expressed directly in terms of attenuation and phase constants of the material.

\section{II -Computation of emissivity and brightness temperature}

The microwave radiometer calculates brightness temperature $\mathbf{T}_{\mathbf{B}}$ which is in general, a function of the physical temperature distribution in the subsurface and the dielectric properties of the medium(Lytle, 1974; Rosenkranz, 2003). The brightness temperature is simply expressed (Wilheit, 1978) as:

$\mathrm{T}_{\mathrm{B}}=\mathrm{R} \mathrm{T}_{\text {ground }}+\left(1-\mathrm{E}_{\mathrm{m}}\right) \mathrm{T}_{\mathrm{sk} y}$ 
Where $\mathbf{T}_{\text {ground }}=$ temperature of the ground (earth) in degree Kelvin, $\mathbf{T}_{\text {sky }}=$ temperature of the sky, and $\mathbf{E}_{\mathbf{m}}=$ the effective emissivity which is related to the reflectivity $\mathbf{R}$ (Ramo et al., 1965).

Emissivity depends on the dielectric constant and to a lesser degree on surface roughness. Although most natural earth surfaces are not electromagnetically smooth at microwave frequencies, however, the dependence of emissivity on surface roughness has been omitted in the present calculation. For a smooth surface, the emissivity in both polarization(p) is expressed as:

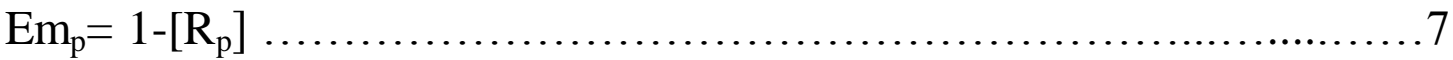

In radiometry, it is seldom necessary to go beyond this Rayleigh- Jeans law. The maximum power that any material can radiate is that of a blackbody i.e. $\mathbf{0}<\mathbf{E}_{\mathbf{m}}<\mathbf{1}$.

For a smooth surface, the reflection from a specular surface boundary is governed by Snell's law and is given by Hidy (1972); Yadav and Gandhi (1992).

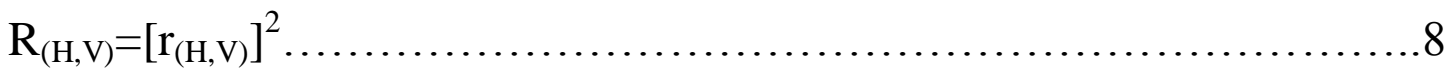

$$
\begin{aligned}
& \mathrm{R}_{\mathrm{H}}=\left[\left\{\operatorname{Cos} \theta-\left(\varepsilon_{\mathrm{r}}-\sin ^{2} \theta\right)^{0.5}\right\} /\left\{\operatorname{Cos} \theta-\left(\varepsilon_{\mathrm{r}}-\sin ^{2} \theta\right)^{0.5}\right\}\right]^{2} \ldots \ldots \ldots \ldots \ldots . . . \ldots \\
& \mathrm{R}_{\mathrm{V}}=\left[\left\{\varepsilon_{\mathrm{r}} \cos \theta-\left(\varepsilon_{\mathrm{r}}-\sin ^{2} \theta\right)^{0.5}\right\} /\left\{\varepsilon_{\mathrm{r}} \cos \theta-\left(\varepsilon_{\mathrm{r}}-\sin ^{2} \theta\right)^{0.5}\right\}\right]^{2} \ldots \ldots \ldots \ldots . .10
\end{aligned}
$$

Where $\mathrm{R}$ is the reflectivity in both horizontal and vertical polarization, $\mathrm{r}_{\mathrm{H}}, \mathrm{r}_{\mathrm{V}}$ are power reflection coefficients in both $(\mathrm{H}, \mathrm{V})$ polarizations. $\boldsymbol{\varepsilon}_{\mathbf{r}}$ is the relative complex dielectric constant $\left(\boldsymbol{\varepsilon}_{\mathbf{r}}=\boldsymbol{\varepsilon}_{1}-\mathbf{j} \boldsymbol{\varepsilon}_{2}\right)$ and $\boldsymbol{\theta}$ is the incidence angle relative to nadir.

\section{EMPIRICAL MODEL OF DIELECTRIC CONSTANTSPACE FOR WET SOILS}

An empirical model for the complex dielectric constant of soils as a function of moisture content was developed by Wang and Schmugge (1980), who expressed dielectric constant of a soil-water mixture in terms of dielectric constants of the 
constituents. Wang and Schmugge applied the regression analysis related to the values of transition moisture $\mathrm{wt}\left(\mathrm{cm}^{3} / \mathrm{cm}^{3}\right)$ and with wilting point $\mathrm{wp}\left(\mathrm{cm}^{3} / \mathrm{cm}^{3}\right)$ of the soils by the relation (Wang and Schmugge, 1980):

$$
\begin{aligned}
& \mathrm{Wt}=0.49 * \mathrm{wp}+0.165 \\
& \text { Parameter } \Omega=0.481-0.57 * \mathrm{wp}
\end{aligned}
$$

Where both $\mathrm{Wt}$ and $\Omega$ have the dimensions of wp, which is a volume ratio $\left(\mathrm{cm}^{3} / \mathrm{cm}^{3}\right)$. The wilting point defined as the soil moisture at which the release of water to a plant is too small to counter balance the transpiration losses. The wp can be calculated from the texture of the soils using the following relation (Wang and Schmugge, 1980):

$$
\mathrm{Wp}=0.06774-0.00064 * \text { sand } \%+0.00478 * \text { clay } \%
$$

Sand and clay are the amounts (in percent) of sand and clay in the soil. The porosity $\mathrm{P}$ of soil can be calculated using the relations (Srivastava and Mishra, 2004; Gadani, and Vyas, 2008):

$$
\mathrm{P}=\left(\mathrm{G}^{*} \rho_{\mathrm{w}}-\rho_{\mathrm{s}}\right) / \mathrm{G}^{*} \rho_{\mathrm{w}}
$$

Where $\mathbf{G}$ is 2.65 , and $\boldsymbol{\rho}_{\mathbf{w}}$ is density of water and $\boldsymbol{\rho}_{\mathbf{s}}$ is density of sample. The

\begin{tabular}{|c|c|c|c|c|c|c|c|}
\hline \multicolumn{3}{|c|}{ Soil texture\% } & \multirow{2}{*}{$\begin{array}{c}\text { wilting } \\
\text { point } \\
\left(\mathrm{cm}^{3} / \mathrm{cm}^{3}\right)\end{array}$} & \multirow{2}{*}{$\begin{array}{l}\text { Transition } \\
\text { moisture } \\
\left(\mathrm{cm}^{3} / \mathrm{cm}^{3}\right)\end{array}$} & \multirow{2}{*}{$\begin{array}{l}\text { Skin depth } \\
\text { (cm) }\end{array}$} & \multirow{2}{*}{$\begin{array}{l}\text { Density } \\
\left(\mathrm{gm} / \mathrm{cm}^{3}\right)\end{array}$} & \multirow[t]{2}{*}{ Porosity } \\
\hline Sand & Silt & Clay & & & & & \\
\hline 94 & 5.4 & 0.6 & 0.0095 & 0.1697 & 0.4759 & 1.70 & 0.3585 \\
\hline 93 & 6.0 & 1.0 & 0.0120 & 0.1708 & 0.4741 & 1.72 & 0.3509 \\
\hline 91 & 7.2 & 2.8 & 0.0229 & 0.1762 & 0.468 & 1.75 & 0.3396 \\
\hline 86 & 11.8 & 2.2 & 0.0232 & 0.1764 & 0.4678 & 1.65 & 0.3774 \\
\hline 96 & 3.2 & 0.8 & 0.0077 & 0.1688 & 0.4766 & 1.75 & 0.3396 \\
\hline
\end{tabular}
values of soil texture wp, wt, $\boldsymbol{\delta}$, porosity, and density of soil sample used in this study are shown in (table 1).

Table 1: Physical properties of the soil used for dielectric measurements.

\section{SAMPLES PREPARATION AND EXPERIMENTAL RESULTS}

The soil samples were collected from many places near Markib seashore of Mediterranean Sea, Libya in April 2002. Dry sand soil samples were prepared before carrying out the experimental observations. Samples were first evenly crushed into fine grains and then the sieved sample was heated to $110^{\circ} \mathrm{C}$ for half 
an hour. This dried out the sample completely and the sample was ready for the experiment. Wet soils were prepared and water-content on a weight basis was determined. The gravimetric soil moisture content (Wc\%) was calculated using wet (W1) and dry (W2) soil masses following the relation: (Calla, 2000).

$$
\mathrm{W}_{\mathrm{C}} \%=\frac{\boldsymbol{w 1}-\boldsymbol{W} \mathbf{2}}{\boldsymbol{w} \mathbf{2}} \times 100
$$

Intensive experiments were carried out to measure the complex dielectric constant $\left(\boldsymbol{\varepsilon}_{1}-\mathbf{j} \boldsymbol{\varepsilon}_{2}\right)$ of the soil using waveguide technique in the microwave frequencies with varying moisture content. The technique used in the measurement is shown in (Fig.1 A and B), the measurement procedure used was described in detail by (Sucher and Fox, 1963; Lytle, 1974; Ulaby, 1974 and; Singh and Singh, 1981). The statistical results of these measurements were shown in (Fig. 2). It was found that the dielectric constant (real and imaginary parts) of these soils increases only slowly with moisture content initially, and after reaching a transition point, it increases rapidly with increasing moisture content in the microwave frequency range.

The results were compared with those of Yadav and Gandhi (1992) and Njoku and Kong (1977). A qualitative difference between the present calculation and that of Chaudhari and Shinde (2008), Njoku and Kong (1977) was that the rate of increase in real part of the complex dielectric constant was more in case of $15 \%$ to $30 \%$ moisture content, whereas in case of Njoku and Kong (1977), the rate of increase was seen to be uniform. Such a difference between the results could be interpreted in terms of different types of soil used in the experiment. Yadav and Gandhi (1992), reported that when water was held in a soil in direct contact with the surface of the soil particles (absorbed), it was characterized to be very different from free water. In particular, the water within few molecules of clay particles might have dielectric constant as small as one-tenth of free water, probably due to the rest

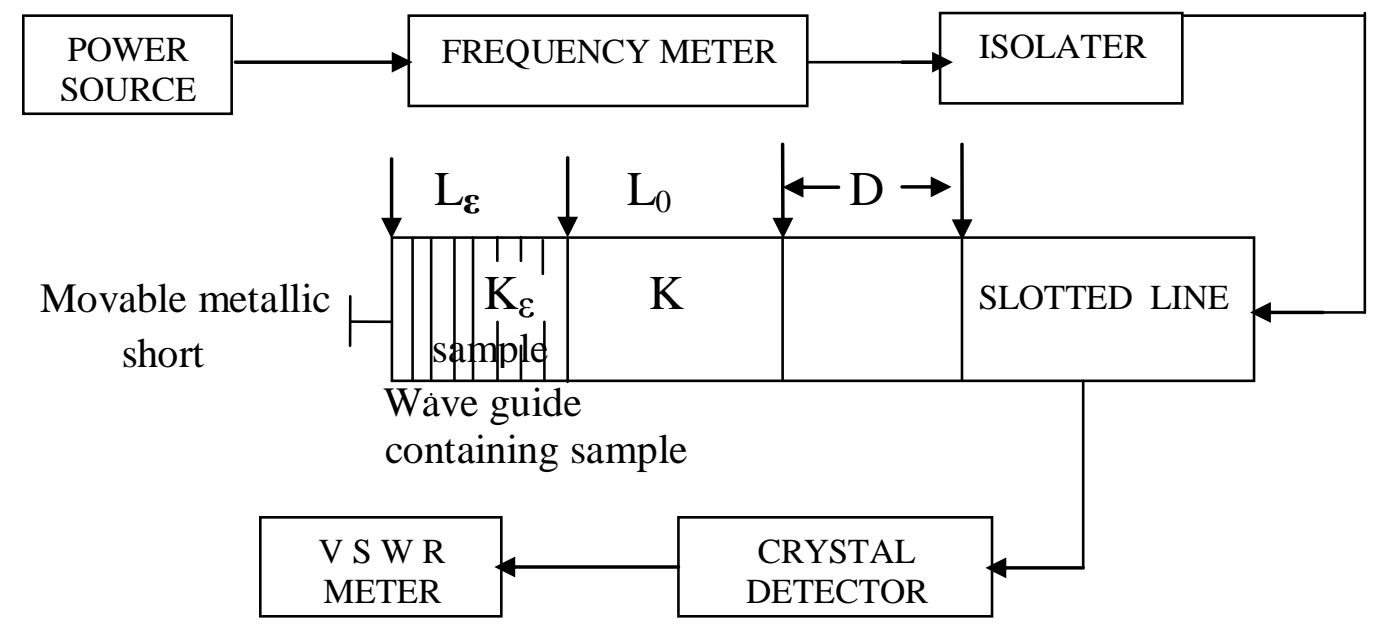

Fig. 1-A : Two Point Method of Measuring Dielectric Constant at $\lambda=2.8 \mathrm{~cm}$. 


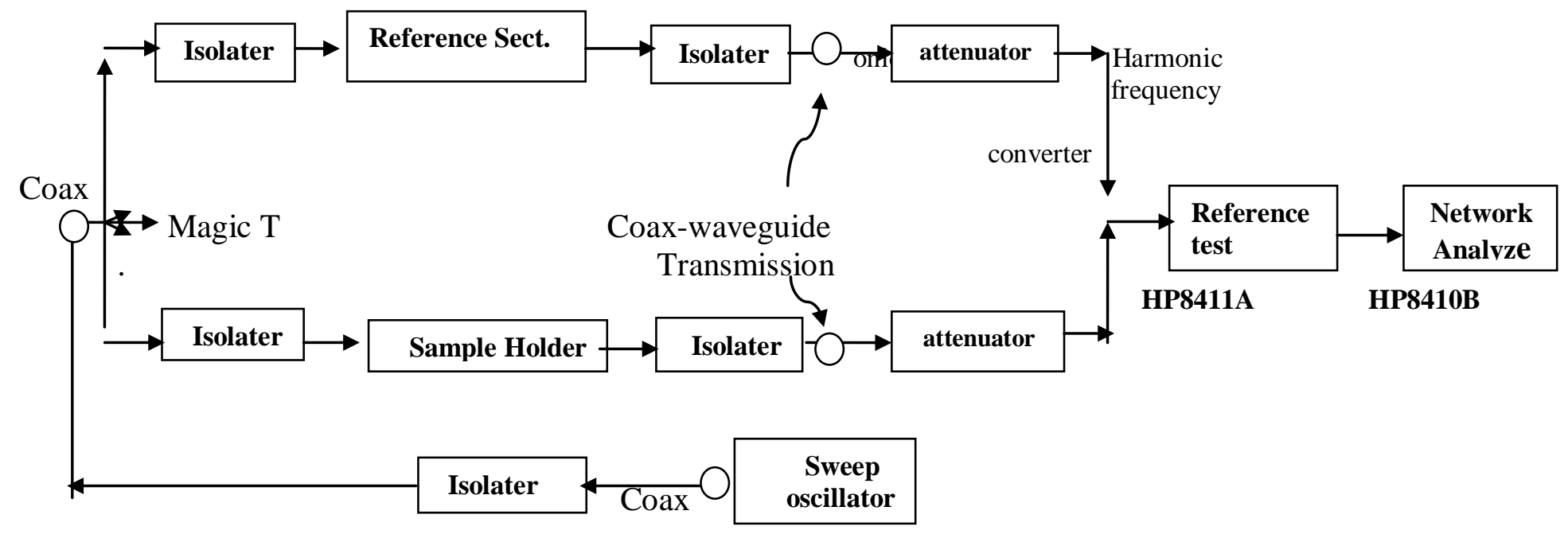

Fig. 1-B: Block Diagram of the Dielectric Measurement System at $\lambda=21 \mathrm{~cm}$.

\section{RESULTS AND DISCUSSION}

The measured values of the dielectric constant $\left(\boldsymbol{\varepsilon}_{\mathbf{1}}\right)_{\text {Real }}$ and $\left(\boldsymbol{\varepsilon}_{\boldsymbol{2}}\right)_{\text {Imaginary }}$ at microwave frequency for sandy soil samples are plotted against various values of moisture content. The results of these measurements are shown in (Fig. 2) and in (table 2). It is found that the dielectric constant (real and imaginary parts) of these soils increases slowly with moisture content initially, and after reaching a transition point, it increases rapidly. This observation is qualitatively in good agreement with the results of (Vyas, 1982; and Wang and Schmugge, 1980). At moisture contents below the transition point due to the presence of only few free water molecules, the mixture dielectric permittivities increase only slowly, whereas at moisture contents above the transition point, the number of free water molecules increases rapidly and hence a steep rise in permittivity is observed.

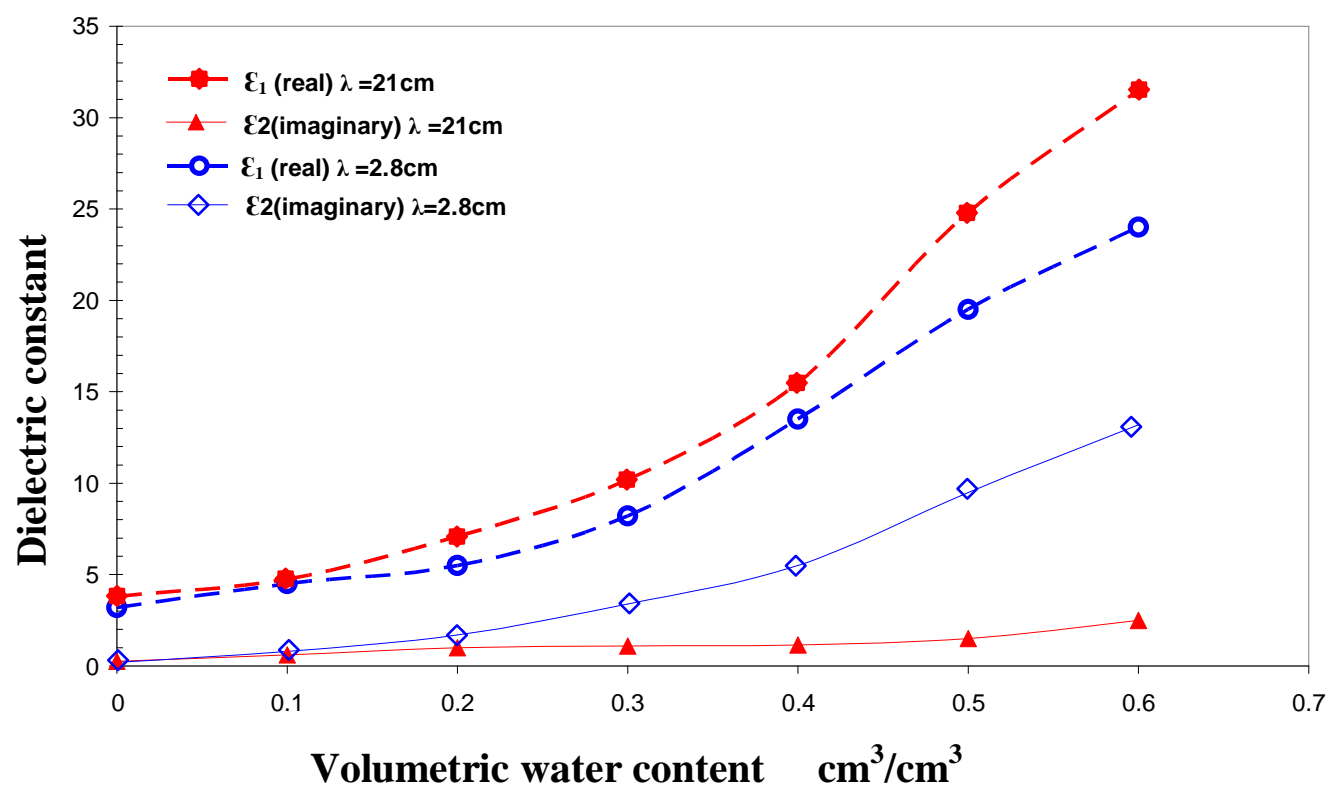


Fig. 2: Mmeasured Values of $\varepsilon_{1}$ and $\varepsilon_{2}$ Versus Moisture Content for Sandy Soils Samples at $(\lambda=21 \mathrm{~cm}$ and $\lambda=2.8 \mathrm{~cm})$.

Table 2: The Measured Values of $\varepsilon_{1}$ and $\varepsilon_{2}$ with Moisture Content of Sandy Soils at $(\lambda=21 \mathrm{~cm}$ and $\lambda=2.8 \mathrm{~cm})$.

\begin{tabular}{|c|c|c|c|c|}
\hline & \multicolumn{2}{|c|}{$\begin{array}{c}\text { Dielectric constant of soil } \\
\boldsymbol{\lambda}=\mathbf{2 1} \mathbf{c m}\end{array}$} & \multicolumn{2}{c|}{$\begin{array}{c}\text { Dielectric constant of soil } \\
\boldsymbol{\lambda}=\mathbf{2 . 8} \mathbf{c m}\end{array}$} \\
\hline Moisture & $\left(\boldsymbol{\varepsilon}_{\mathbf{1}}\right)_{\text {Real }}$ & $\left(\boldsymbol{\varepsilon}_{\mathbf{2}}\right)_{\text {Imaginary }}$ & $\left(\boldsymbol{\varepsilon}_{\mathbf{1}}\right)_{\text {Real }}$ & $\left(\boldsymbol{\varepsilon}_{\mathbf{2}}\right)_{\text {Imaginary }}$ \\
\hline 0 & 3.8 & 0.25 & 3.2 & 0.2 \\
\hline 0.1 & 4.75 & 0.6 & 4.5 & 0.8 \\
\hline 0.2 & 7.1 & 1.0 & 5.5 & 1.7 \\
\hline 0.3 & 10.2 & 1.1 & 8.2 & 3.4 \\
\hline 0.4 & 15.5 & 1.15 & 13.5 & 5.5 \\
\hline 0.5 & 24.8 & 1.5 & 19.5 & 9.5 \\
\hline 0.6 & 31.5 & 2.5 & 24 & 13.2 \\
\hline
\end{tabular}

Using these laboratory data, the reflectivity and emissivity of the surface medium have been computed at nadir and at varying look angles using the relations (7-10). The variation of the reflectivity and emissivity is shown in figures $(3,4)$ respectively, tables $(3,4)$. The results show that the presence of moisture in soil causes a marked change in reflectivity and emissivity. The reflectivity is found to vary from 0.22 to 0.63 , whereas emissivity changes in opposite direction and varies from 0.9 to 0.51 from dry surface to 30 percent moisture. The change in reflectivity and emissivity for a soil has been observed by trucks mounted radiometers in field experiment (Ulaby, 1974).

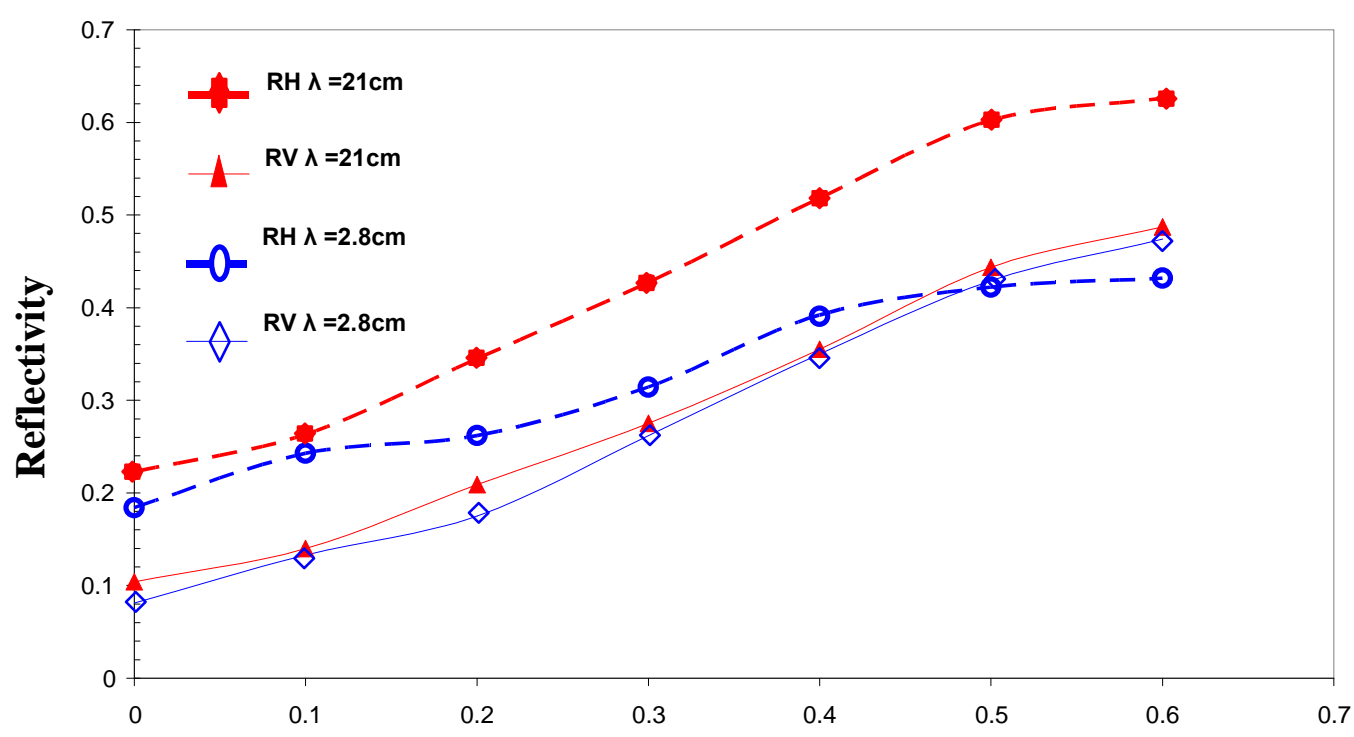

Volumetric water content $\mathrm{cm}^{3} / \mathrm{cm}^{3}$

Fig. 3: Variation of Reflectivity with Moisture Content for Sandy Soils at $(\lambda=21 \mathrm{~cm}$ and $\lambda=2.8 \mathrm{~cm})$. 
Table 3: The Calculated Data of Reflectivity as a Function of the Moisture Content.

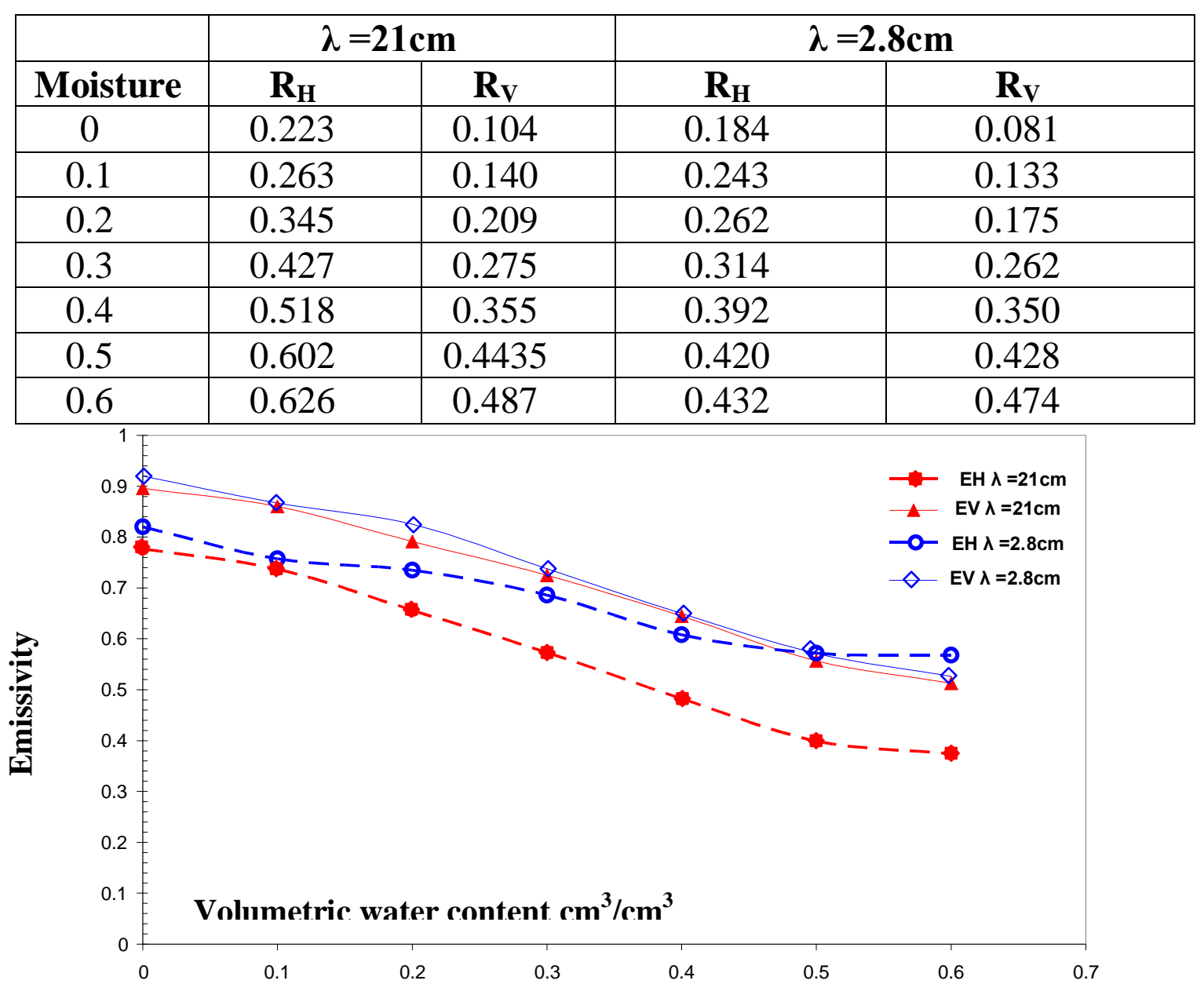

Fig. 4: Variation of Emissivity with Moisture Content for Sandy soils at $(\lambda=21 \mathrm{~cm}$ and $\lambda=2.8 \mathrm{~cm}$ ).

Table 4: The Calculated Data of Emissivity as a Function of the Moisture Content.

\begin{tabular}{|c|c|c||c|c|}
\hline & \multicolumn{2}{|c||}{$\lambda=\mathbf{2 1} \mathbf{c m}$} & \multicolumn{2}{c|}{$\boldsymbol{\lambda}=\mathbf{2 . 8 c m}$} \\
\hline Moisture & $\mathbf{E}_{\mathbf{m H}}$ & $\mathbf{E}_{\mathbf{m V}}$ & $\mathbf{E}_{\mathbf{m H}}$ & $\mathbf{E}_{\mathbf{m V}}$ \\
\hline 0 & 0.777 & 0.896 & 0.82 & 0.92 \\
\hline 0.1 & 0.737 & 0.860 & 0.757 & 0.867 \\
\hline 0.2 & 0.656 & 0.791 & 0.735 & $\mathrm{f} 0.825$ \\
\hline 0.3 & 0.573 & 0.725 & 0.686 & 0.738 \\
\hline 0.4 & 0.482 & 0.645 & 0.608 & 0.650 \\
\hline 0.5 & 0.399 & 0.557 & 0.572 & 0.571 \\
\hline 0.6 & 0.374 & 0.513 & 0.568 & 0.526 \\
\hline
\end{tabular}


As the moisture content of soil increases, the reflectivity increases, whereas the emissivity decreases and the brightness temperature also decreases, the data are explained in (Fig. 5) and shown in (table 5). The results in (Fig. 3, 4 and 5) also show a small variability due to frequency for the cases considered at any moisture content.

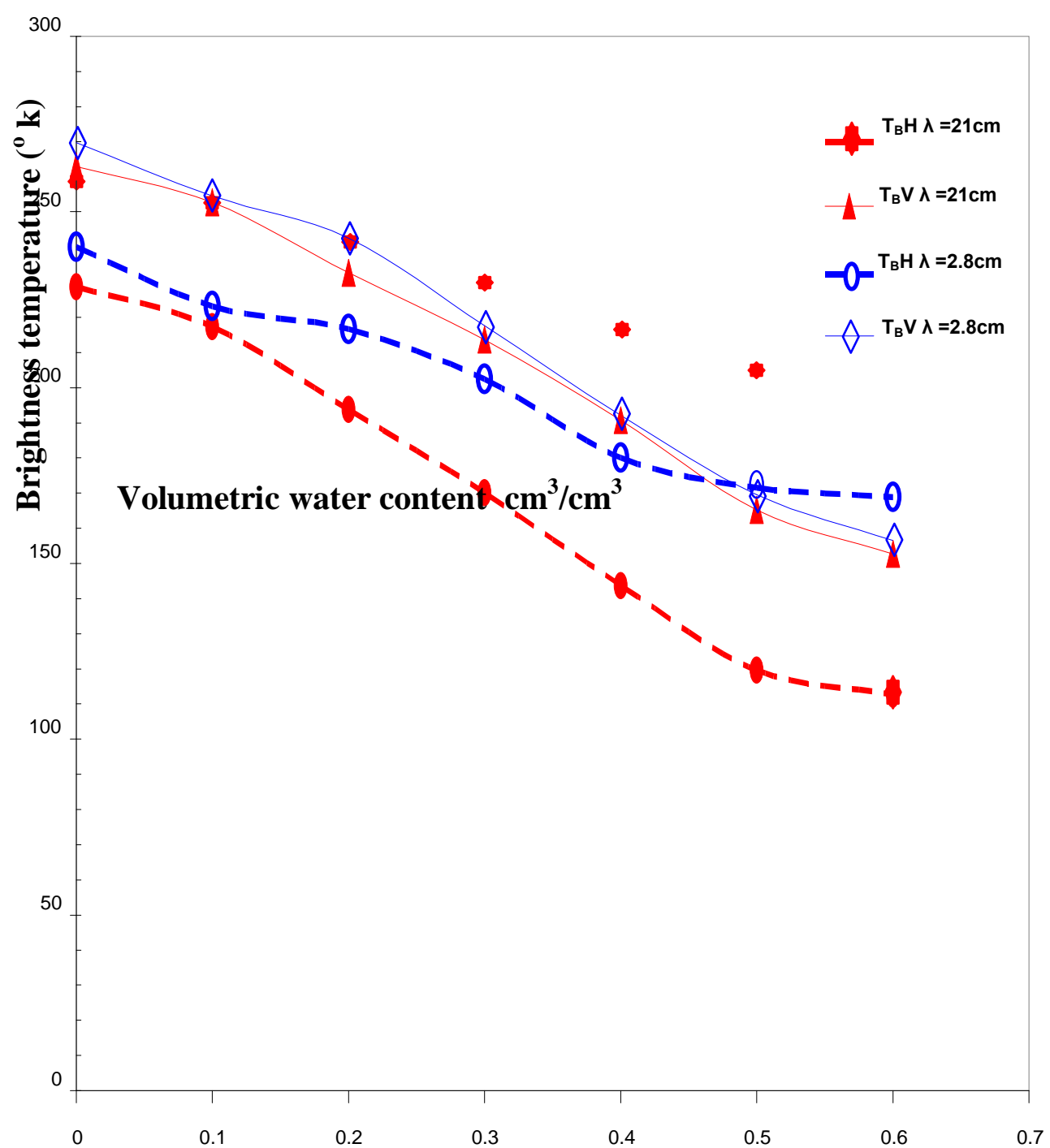

Fig. 5: Variation of Brightness Temperature with Moisture Content for Sandy Soils at $(\lambda=21 \mathrm{~cm}$ and $\lambda=2.8 \mathrm{~cm})$.

Table 5: The Calculated Data of Brightness Temperature as a Function of the Moisture Content.

\begin{tabular}{|c|c|c|c|c|}
\hline & \multicolumn{2}{|c|}{$\lambda=\mathbf{2 1} \mathbf{c m}$} & \multicolumn{2}{c|}{$\boldsymbol{\lambda = \mathbf { 2 . 8 c m }}$} \\
\hline Moisture & $\mathbf{T}_{\mathbf{B H}}$ & $\mathbf{T}_{\mathbf{B V}}$ & $\mathbf{T}_{\mathbf{B H}}$ & $\mathbf{T}_{\mathbf{B V}}$ \\
\hline 0 & 228.67 & 262.99 & 240.1 & 269.8 \\
\hline 0.1 & 217.349 & 252.724 & 223.139 & 254.580 \\
\hline 0.2 & 193.745 & 232.730 & 216.61 & 242.62 \\
\hline 0.3 & 170.039 & 213.685 & 202.491 & 217.582 \\
\hline
\end{tabular}




\begin{tabular}{|c|c|c|c|c|}
\hline 0.4 & 143.723 & 190.838 & 180.073 & 192.089 \\
\hline 0.5 & 119.543 & 165.278 & 171.556 & 169.572 \\
\hline 0.6 & 112.811 & 152.621 & 168.87 & 156.56 \\
\hline
\end{tabular}

It has also been found from (Fig. 6 ),(A, B) and (table 6), (A, B) that the emissivity decreases at larger angles of incidence for horizontal polarization, whereas it increases for vertically polarized case with increasing incidence angle to a maximum occurring at the Brewster angle. It has also been observed that the incident angle, at which the Brewster angle occurs, shifts toward grazing for higher moisture content.

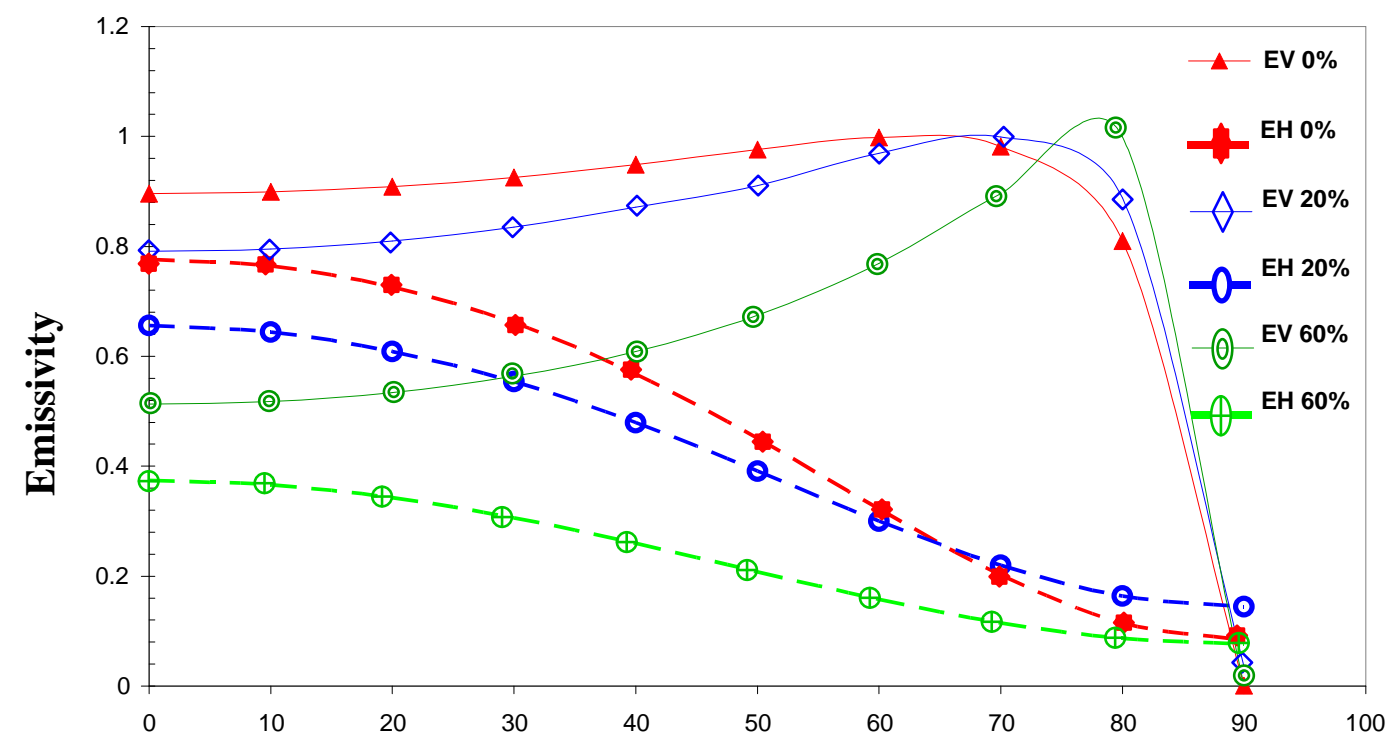

Angle $(\theta)$ degree

Fig. 6 A: Model of Calculated Emissivity as a Function of the Angle at a $\lambda=21 \mathrm{~cm}$, the Ascending Curve is for Vertical and the Descending Curve is for Horizontal Polarizations.

Table 6 A: The Calculated Data from Model for Emissivity at Moisture $(0,20 \%, 60 \%)$ as a function of angle at $\lambda=21 \mathrm{~cm}$.

\begin{tabular}{|c|c|c|c|c|c|c|}
\hline & \multicolumn{2}{|c|}{ moisture=0\% } & \multicolumn{2}{l|}{ moisture=20\% } & \multicolumn{2}{c|}{ moisture=60\% } \\
\hline Angle & $\mathbf{E}_{\mathbf{m H}}$ & $\mathbf{E}_{\mathbf{m V}}$ & $\mathbf{E}_{\mathbf{m H}}$ & $\mathbf{E}_{\mathbf{m V}}$ & $\mathbf{E}_{\mathbf{m H}}$ & $\mathbf{E}_{\mathbf{m V}}$ \\
\hline 0 & 0.7766 & 0.8958 & 0.656 & 0.7909 & 0.374 & 0.513 \\
\hline 10 & 0.7643 & 0.8991 & 0.644 & 0.7954 & 0.366 & 0.518 \\
\hline 20 & 0.7263 & 0.9090 & 0.609 & 0.8100 & 0.343 & 0.534 \\
\hline 30 & 0.661 & 0.9256 & 0.554 & 0.8350 & 0.306 & 0.564 \\
\hline
\end{tabular}




\begin{tabular}{|c|c|c|c|c|c|c|}
\hline 40 & 0.5675 & 0.9488 & 0.4791 & 0.8711 & 0.260 & 0.609 \\
\hline 50 & 0.4505 & 0.9762 & 0.3910 & 0.9110 & 0.208 & 0.675 \\
\hline 60 & 0.3217 & 0.9980 & 0.300 & 0.9696 & 0.158 & 0.769 \\
\hline 70 & 0.2016 & 0.9815 & 0.2196 & 0.9989 & 0.115 & 0.896 \\
\hline 80 & 0.1150 & 0.8095 & 0.1640 & 0.8878 & 0.0869 & 0.999 \\
\hline 90 & 0.0833 & 0.00042 & 0.1441 & 0.000536 & 0.0769 & 0.00106 \\
\hline
\end{tabular}

\section{Angle ( $\theta)$ degree}

Fig. 6 B: Model of Calculated Emissivity as a Function of the Angle at $\lambda=2.8 \mathrm{~cm}$, the Ascending Curve is for Vertical and the Descending curve is for horizontal polarizations.

Table 6 B: The Calculated Data from Model for Emissivity at Moisture $(0,20 \%, 60 \%)$ as a Function of Angle at $\lambda=2.8 \mathrm{~cm}$.

\begin{tabular}{|c|c|c|c|c|c|c|}
\hline & \multicolumn{2}{|c|}{ moisture=0\% } & \multicolumn{2}{c|}{ moisture=20\% } & \multicolumn{2}{c|}{ moisture=60\%. } \\
\hline Angle & $\mathbf{E}_{\mathbf{m H}}$ & $\mathbf{E}_{\mathbf{m V}}$ & $\mathbf{E}_{\mathbf{m H}}$ & $\mathbf{E}_{\mathbf{m V}}$ & $\mathbf{E}_{\mathbf{m H}}$ & $\mathbf{E}_{\mathbf{m V}}$ \\
\hline 0 & 0.8162 & 0.9195 & 0.735 & 0.825 & 0.568 & 0.526 \\
\hline 10 & 0.8042 & 0.9222 & 0.725 & 0.829 & 0.563 & 0.532 \\
\hline 20 & 0.7672 & 0.931 & 0.695 & 0.843 & 0.546 & 0.548 \\
\hline 30 & 0.7021 & 0.945 & 0.646 & 0.866 & 0.521 & 0.578 \\
\hline 40 & 0.6071 & 0.964 & 0.58 & 0.898 & 0.488 & 0.623 \\
\hline 50 & 0.485 & 0.985 & 0.501 & 0.939 & 0.452 & 0.689 \\
\hline 60 & 0.3474 & 0.9998 & 0.419 & 0.981 & 0.417 & 0.781 \\
\hline 70 & 0.21627 & 0.9732 & 0.347 & 0.991 & 0.387 & 0.901 \\
\hline 80 & 0.12022 & 0.7906 & 0.296 & 0.856 & 0.368 & 0.984 \\
\hline 90 & 0.08474 & 0.0004 & 0.278 & 0.00048 & 0.361 & 0.00096 \\
\hline
\end{tabular}

For uniform moisture content and temperature distribution, the brightness temperature of the surface has been computed in both polarizations using the 
relation in equation (6) as in (Table $7 \mathrm{~A}, \mathrm{~B}$ ). (Fig. $7 \mathrm{~A}, \mathrm{~B}$ ) show the brightness of the medium, and is found to vary from $262^{\circ} \mathrm{K}$ from dry soil down to $152^{\circ} \mathrm{K}$ for wet soil. It has also been observed that brightness is independent of frequency. (Fig.7A, B) illustrates the use of microwave radiometers to locate the moisture.

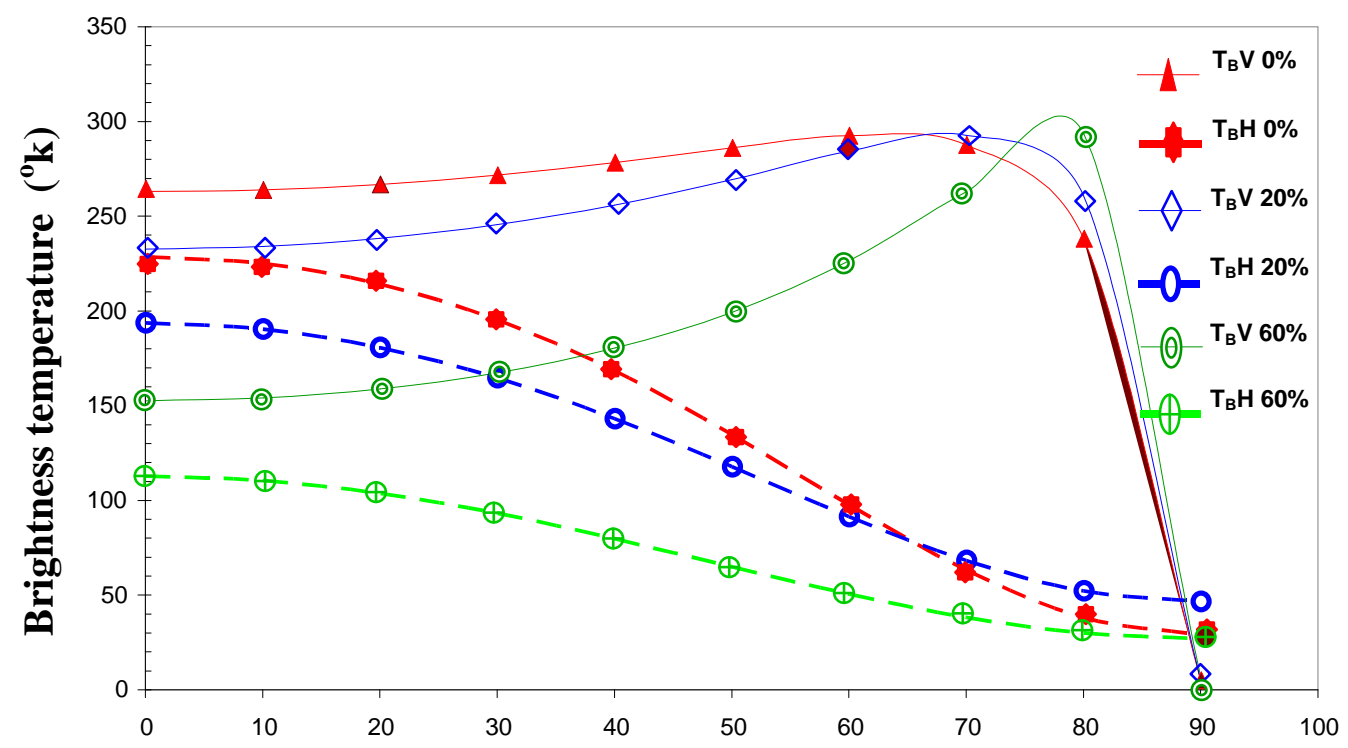

Angle $(\theta)$ degree

Fig. 7 A: Emission Model Predictions of Brightness Temperature for Sandy soil as a Function of the Angle at $\lambda=21 \mathrm{~cm}$, the Ascending Curve is for Vertical and the Descending Curve is for Horizontal Polarizations.

Table 7 A: The Calculated Data from Model for Brightness Temperature at Moisture $(0,20 \%, 60 \%)$ as a Function of Angle at $\lambda=21 \mathrm{~cm}$.

\begin{tabular}{|c|c|c|c|c|c|c|}
\hline & \multicolumn{2}{|c|}{ moisture=0\%. } & \multicolumn{2}{l|}{ moisture=20\%. } & \multicolumn{2}{c|}{ moisture=60\%. } \\
\hline Angle & $\mathbf{T}_{\mathbf{B H}}$ & $\mathbf{T}_{\mathbf{B V}}$ & $\mathbf{T}_{\mathbf{B H}}$ & $\mathbf{T}_{\mathbf{B V}}$ & $\mathbf{T}_{\mathbf{B H}}$ & $\mathbf{T}_{\mathbf{B V}}$ \\
\hline 0 & 228.67 & 262.99 & 193.7448 & 232.73 & 112.811 & 152.621 \\
\hline 10 & 225.11 & 263.93 & 190.469 & 234.10 & 110.505 & 154.154 \\
\hline 20 & 214.17 & 266.78 & 180.674 & 238.296 & 103.769 & 158.901 \\
\hline 30 & 195.32 & 271.58 & 164.584 & 245.495 & 93.180 & 167.343 \\
\hline 40 & 168.43 & 278.27 & 142.983 & 255.91 & 79.737 & 180.375 \\
\hline 50 & 134.73 & 286.13 & 117.617 & 269.389 & 64.877 & 199.448 \\
\hline 60 & 97.66 & 292.44 & 91.414 & 284.252 & 50.382 & 226.599 \\
\hline 70 & 63.06 & 287.67 & 68.262 & 292.70 & 38.181 & 263.021 \\
\hline 80 & 38.13 & 238.13 & 52.240 & 260.7 & 30.028 & 292.89 \\
\hline 90 & 29.00 & 0.000512 & 26.5 & 0.0005154 & 27.161 & 0.0005304 \\
\hline
\end{tabular}




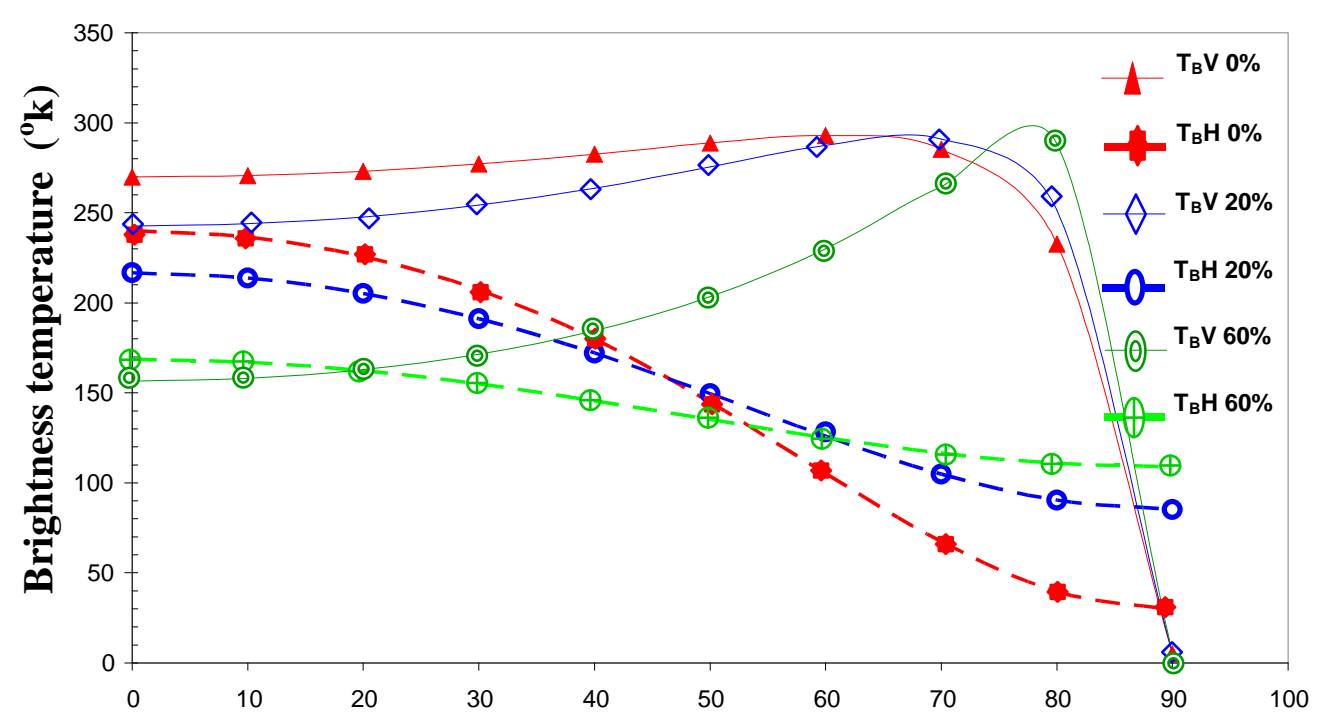

Angle $(\theta)$ degree

Fig.7 B: Emission Model Predictions of Brightness Temperature for Sandy Soil as a Function of the Angle at $\lambda=2.8 \mathrm{~cm}$, the Ascending Curve is for Vertical and the Descending Curve is for Horizontal Polarizations.

Table 7 B: The Calculated Data from Model for Brightness Temperature at Moisture $(0,20 \%, 60 \%)$ as a Function of Angle at $\lambda=2.8 \mathrm{~cm}$.

\begin{tabular}{|c|c|c|c|c|c|c|}
\hline & \multicolumn{2}{|c|}{ moisture=0\% } & \multicolumn{2}{c|}{ moisture=20\% } & \multicolumn{2}{c|}{ moisture=60\%. } \\
\hline Angle & $\mathbf{T}_{\mathbf{B H}}$ & $\mathbf{T}_{\mathbf{B V}}$ & $\mathbf{T}_{\mathbf{B H}}$ & $\mathbf{T}_{\mathbf{B V}}$ & $\mathbf{T}_{\mathbf{B H}}$ & $\mathbf{T}_{\mathbf{B V}}$ \\
\hline 0 & 240.1 & 269.82 & 216.61 & 242.62 & 168.686 & 156.564 \\
\hline 10 & 236.62 & 270.61 & 213.77 & 243.89 & 167.079 & 158.114 \\
\hline 20 & 225.94 & 272.998 & 205.25 & 247.75 & 162.383 & 162.91 \\
\hline 30 & 207.20 & 277.02 & 191.15 & 254.33 & 154.995 & 171.414 \\
\hline 40 & 179.89 & 282.54 & 172.03 & 263.71 & 145.609 & 184.478 \\
\hline 50 & 144.68 & 288.80 & 149.39 & 275.48 & 135.227 & 203.440 \\
\hline 60 & 105.06 & 292.9303 & 125.82 & 287.43 & 125.098 & 230.035 \\
\hline 70 & 67.28 & 285.2871 & 104.90 & 290.88 & 116.571 & 264.549 \\
\hline 80 & 39.62 & 232.6835 & 90.37 & 251.48 & 110.873 & 288.263 \\
\hline 90 & 29.41 & 0.005115 & 46.16 & 0.00514 & 64.869 & 0.005275 \\
\hline
\end{tabular}

Microwave energy, which is radiated from the earth's surface, is polarized in both horizontal and vertical planes. The computed values of brightness temperatures of water-bearing soils are in both polarizations. The vertical polarized microwaves read out higher brightness temperature, and is maximum at the Brewster angle about $70^{\circ}-80^{\circ}$ whereas the horizontally polarized microwaves show the lesser values for the same moisture content of decreasing trend. Therefore, the use of both polarizations are potentially useful to estimate the moisture content of 
soil. These parameters (emissivity and brightness temperature) have been widely used in developing inversion model, which is helpful for interpretation of remote sensing data obtained by air-borne satellite and ground-based satellite. The brightness temperature and emissivity of earth's surfaces are obtained by groundbased or satellite-base. Sensors are inverted to laboratory measured microwave parameters using suitable inversion algorithms for deriving soil moisture.

\section{CONCLUSION}

The conclusions obtained from this study are as follows:

1-Soil moisture is a very important geosciences parameter for both application and scientific research purposes. The soil moisture monitoring is certainly possible by passive microwave radiometry, but the questions of how much soil could be monitored, its moisture range and how the types of soil affect the accuracy of the monitor are not yet clear. Therefore, these problems along with some parameters which affect the microwave signature, require detailed study to develop an appropriate inversion model.

2- Additional experiments are also required to demonstrate the feasibility of obtaining the required temperature measurements from aircrafts as possibly satellite-based remote sensors and to more precisely the depth to which water contents may be inferred from surface temperature measurements.

\section{Nomenclature:}

$\left(\varepsilon_{1}\right)$ Real $=$ Dielectric constant (real value).

$\left(\varepsilon_{2}\right)$ Imaginary $=$ Dielectric constant (image value).

$\mathrm{P}=$ Polarization.

$\mathrm{H}=$ Horizontal polarization.

$\mathrm{V}=$ Vertical polarization.

$\mathrm{R}=$ Reflectivity.

$\mathrm{E}_{\mathrm{m}}=$ Emissivity.

$\mathrm{T}_{\mathrm{B}}=$ Brightness temperature.

$\mathrm{T}_{\text {ground }}=$ Surface temperature (Physical temperature).

$\mathrm{T}_{\text {sky }}=$ Sky temperature.

$\mathrm{L}_{\varepsilon}=$ Length of sample in the waveguide.

$\mathrm{L}_{0}=$ Length in the empty waveguide.

$\mathrm{K}=$ The propagation constant (in the empty waveguide).

$\mathrm{K}_{\varepsilon}=$ The propagation constant (with sample in the waveguide).

$\mathrm{D}=$ The position of the minimum in the slotted line, with respect to the reference plane $(\mathrm{D}=0)$. 


\section{REFERENCES}

Calla, O. P. N., 2000. Study of the Emissivity of Dry and Wet Loamy Sand Soils at Microwave Frequency. Indian J. Radio Space Phys., Vol. 29, pp. 144 - 154. E-mail: opncalla@yahoo.co.in.

Chaudhari, H. C. and Shinde, V. J., 2008. Dielectric Study of Moisture Laden Soilsat X- band Microwave Frequency. International J. of Phys. Sciences, Vol. 3, No.3, pp.75 - 78. http://www.academicjournals.org/IJPS

Gadani, D. H. and Vyas, A. D., 2008. Measurement of Complex Dielectric Constant of Soils of Gujarat at Microwave Frequencies. Indian j. of Radio and Space Physics, Vol. 37, pp. 221 - 229. E-mail: dhgadani@yahoo.com

Hidy, G. M., Hall,W. F., and Hardy, W. N., 1972. Development of a Satellite Microwave Radiometer to Sense the Surface Temperature of the World Oceans, NASA CRA, North American Rockwell Corporation, Downey, California.

Lytle, R. J., 1974. Measurement of Earth Medium Electrical Characteristic: Technique, Result and Applications. IEEE. GeoSci. Electron, Vol. GE-12, pp. $81-101$.

Njoku, E. G. and Kong, J. A., 1977. Theory for Passive Microwave Sensing of Near-Surface Soil Moisture. J. Geo phys. Res., Vol. 82, PP. 3108 - 3118.

Pancholi, K. C. and Khameshra, S. M., 1994. Complex Dielectric Constant of Some Rajasthan soils at 7.114GHz. Indian J. Radio Space Phys., Vol. 23, $201 \mathrm{p}$.

Ramo, W., J. R. Whinnery, and T. Van Duzer,1965. Field and Waves in Communication Electronics. New York, Wiley.

Rosen Kranz, P. W., 2003. Rapid Radiative Transfer Model for AMSU/HSB Channels. IEEE Trans. Geophysics and Remote Sensing, Vol. 41. No. 2, pp. $362-268$

Singh, R. and Singh, K. P., 1981. Laboratory Studies on the Microwave Response of Soil with Particular Reference to Remote Sensing. Proc. Indian Nat. Sci. Acad., Vol. 47, No. 2, pp. 253 - 263.

Srivastava, S. K. and Mishra, G. P., 2004. Study of the Characteristics of the Soil of Chhattisgarh at X-band Frequency. $S^{-}$adhan $^{-} a$, Printed in India ,Vol. 29, Part 4, pp. 343 - 347. E-mail: sk-srivastava@yahoo.com

Stratton, J. A., 1944. Electromagnetic Theory. New York, Mc Graw Hill book Co. Inc.

Sucher, M. and Fox, J., 1963. Hand Book of Microwave Measurements. New York Poly Technique Press. $3^{\text {rd }}$ Ed., Vol. 2, Chap. 9, pp. 495 - 548.

Uluby, F. T., More, R. K. and Fung, A. K., 1986. Microwave Remote Sensing; Active and Passive from Theory to Application, Vol. 3, U.S.A., Artech House, 2162 p.

Uluby, F.T., 1974. Radar Measurement of Soil Moisture Content, IEEE Trans. Antenna and Propagat. ,Vol. Ap-22, No. 2, pp. 257 - 265. 
Vyas, A. D. and Gadam, D.H., 2001. Study of Complex Dielectric Constants of Soils of Gujarat at X-band and C-band Microwave Frequencies, physical Methods of Soils Characterization. Indian J. of Radio and Space Physics, Vol. 37, pp. 221 - 229. E-mail: dhgadani@yahoo.com

Vyas, A. D., 1982. Complex Dielectric Constant of Sandy and Sandy Loam Soils at Microwave Frequencies. Indian J. Radio Space Phys., Vol. 2, pp. 169 - 174.

Wang, J. R. and Schmugge, T. J., 1980. An Empirical Model for the Complex Dielectric Constant of Soils as a Function of Water Constant. IEEE Trans. GRS, Vol. GE-18, No. 4, pp. 288 - 295.

Wilheit, T. T., 1978. Radiative Transfer in a Plane Stratified Dielectric. IEEE Trans. Geosci Election, Vol. GE -16, pp.138 - 143.

Yadav, J. S. and Gandhi, J. M., 1992. Simple Microwave Technique for Measuring the Dielectric Parameters of Solids and their Powders. Indian J. Pure Appl. Phys., Vol. 30, pp. 428 - 431. 